\title{
An Evaluation of Mechanical Properties (Tensile strength \& Elastic Modulus) of Soldered Straight Stainless Steel Wires
}

\author{
Wael Abdul Alrazzaq \\ Lecturer - Middle Technical University/ College of Health \& Medical Technology /Baghdad / Iraq - Prosthetic dentistry depart- \\ ment
}

\begin{abstract}
The joining of a metal framework is frequently necessary to create individual orthodontic appliances and to achieve efficient treatment procedures. Stainless steel wires can be fused together by welding but this generally required reinforcement with solder. The present study was conducted to compare and evaluate the mechanical properties (i.e. the tensile strength and elastic modulus )of silver soldered joints of stainless steel. A total of 40 wire specimens were prepared. The tensile strength and elastic modulus tests were carried out via by universal testing machine. the results indicated that the mean tensile strength of soldered group is lower than that of soldered group. As well, there are highly significant differences between two groups for tensile strength ( $p<0.01)$. Furthermore, the soldered group has the highest mean of elastic modulus than that of control group. As well, there are highly significant differences between two groups for elastic modulus $(p<0.01)$. It is concluded that Stainless steel wires (Remanium)have superior mechanical properties with regard to tensile strength and elastic modulus.
\end{abstract}

\section{KEYWORDS}

Silver solder, Stainless Steel wires

\section{INTRODUCTION}

For orthodontic appliances and space maintainers, the strength of silver soldered joints is critical to their success ${ }^{(1,2)}$. The appliance generally should be able to resist the forces which are generated while masticating. As well, the broken orthodontic appliances induce patients for unprepared office appointments. The main problems of broken appliances comprise lost orthodontic anchorage, soft tissue irritation, unpleasant movement of teeth and swallowing or aspiration of broken parts ${ }^{(2)}$. Research is undertaken regarding the methods and new materials to aid dental surgeons to construct a stronger soldered joints ${ }^{(3-7)}$. Various authors have assessed different soldering techniques than the incorporation of different orthodontic wires to study the tensile strength of soldered joints ${ }^{(8-13)}$. Hence, the present study was carried out to assess and compare the mechanical properties (tensile strength and elastic modulus) of stainless steel wires and soldered wires.

\section{METHOD}

The specimens were assorted in the laboratory of the orthodontic department at college of Health and Medical Technology/Baghdad. The tensile strength and elastic modulus tests were carried out at the department of materials researches, ministry of science and technology.

\section{Preparation of the samples}

Stainless steel wires 0.036 inch (Remanium) were prepared to a length of $(30) \mathrm{cm}$, and samples with a cutter.Then the wires were modified with plier to the straight shape.

\section{Preparation of the soldered samples:}

Twenty samples were fabricated for each gauge of straight stainless steel wires. Two points were determined in the center of the wire with a marker (figure 1) to place the solder on this area.

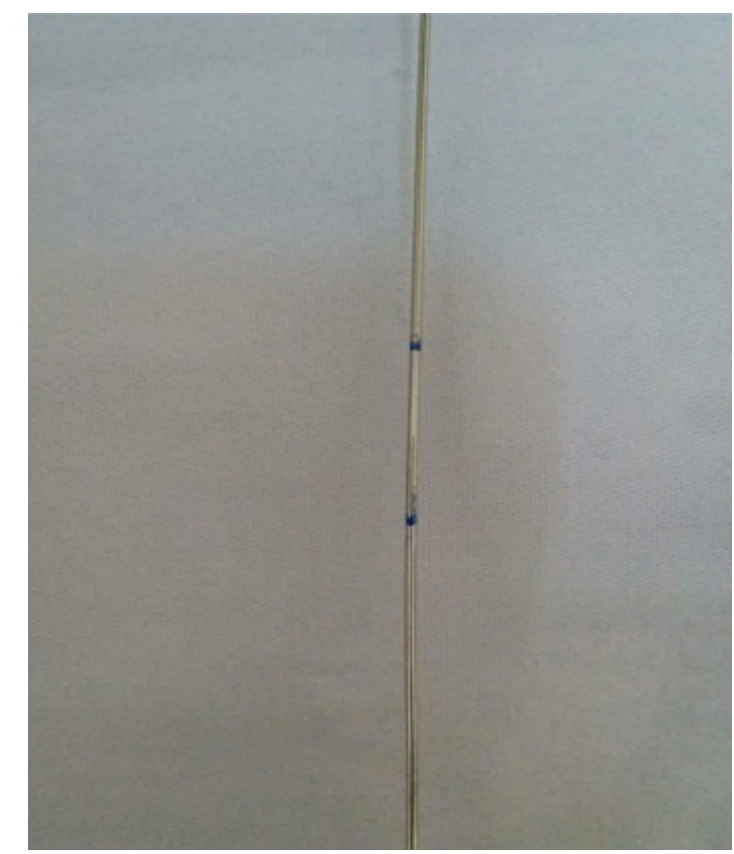

Fig.(1)Preparation of the soldered samples

Ortho technology silver solder was used for soldering. The area site was adequately heated with the reducing zone of the flame and as soon as the site reached solder flow temperature, the soldering was observed in a shadow, against a black back ground , so that the temperature can be judged by the color of the work. The color must not exceed a dull red . The solder was then added; heating was continued 
till the metal flows around the area. The flame was withdrawn when the solder had flown over the area site in a feather edge configuration. After each soldering process, the gas- oxygen torch was re-filled with gas to be sure the size of the flame is equal for all samples ${ }^{(14)}$.

\section{Soldering method:}

A-Distance from the heat source:

Wires were fixed on a customized cartoon board stand to grasp the wire during soldering process as shown on figure (2). The portion of the flame that is used to heat the soldered area was the reducing area (zone)because this produces the most efficient burning process. The work was held $(3 \mathrm{~mm})$ beyond the tip of the blue cone in the reducing zone of the flame to get benefit from the most efficient of the flame (reducing zone) ${ }^{(14)}$.

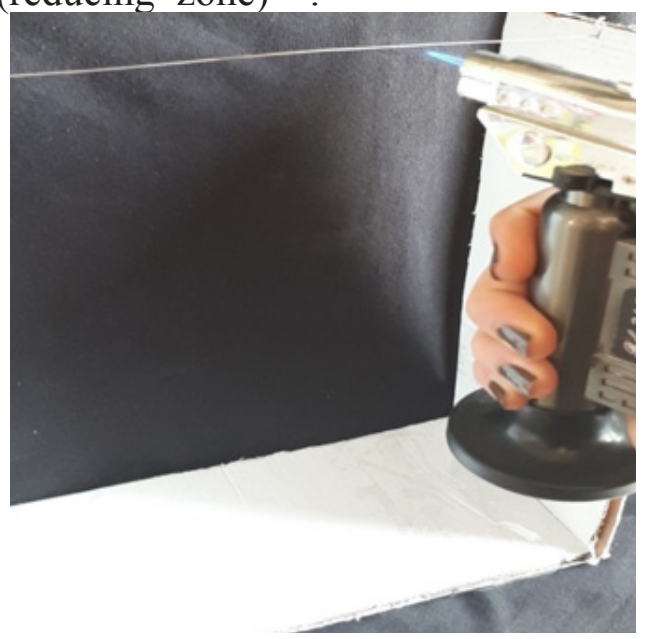

Fig.(2)standardization of wire positioning.

b-Time of heat application:

Each soldered sample was heated for (5 seconds); then solder was applied which takes another (5 seconds) to melt and fill the determined area. The full time of heat exposure on the wire (10 seconds).

\section{Ultimate force and ultimate tensile testing procedure:}

The tests were carried out at the department of materials researches, ministry of science and technology. The universal testing machine (Tinius Olsen $\backslash$ Model $50 \mathrm{KM}$ with a capacity of $50 \mathrm{KN}$ ) was standardized to grasp the wire firmly in a vertical way by mounting wires into capstan grips with a nip- tonip distance of $(10 \mathrm{~mm})$ for fixation of the samples (figures $3 \& 4$ ).

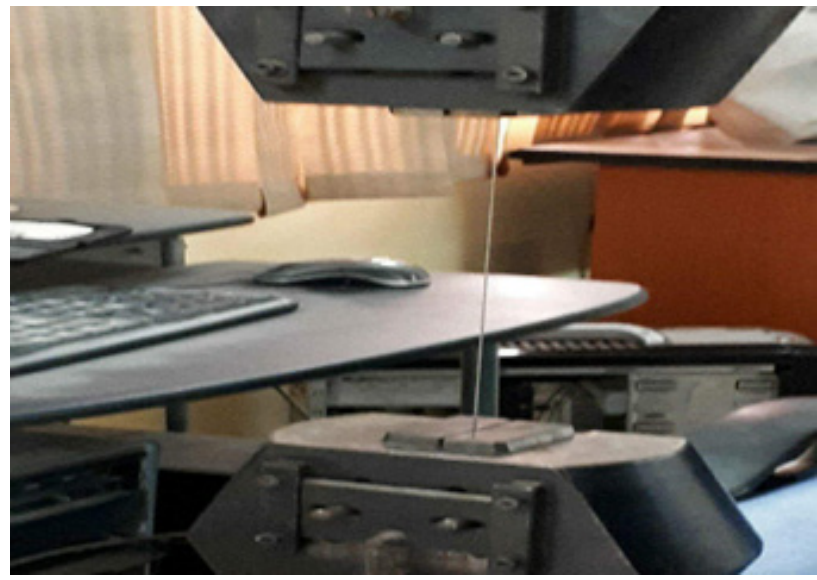

Fig.(3)The sample during the test

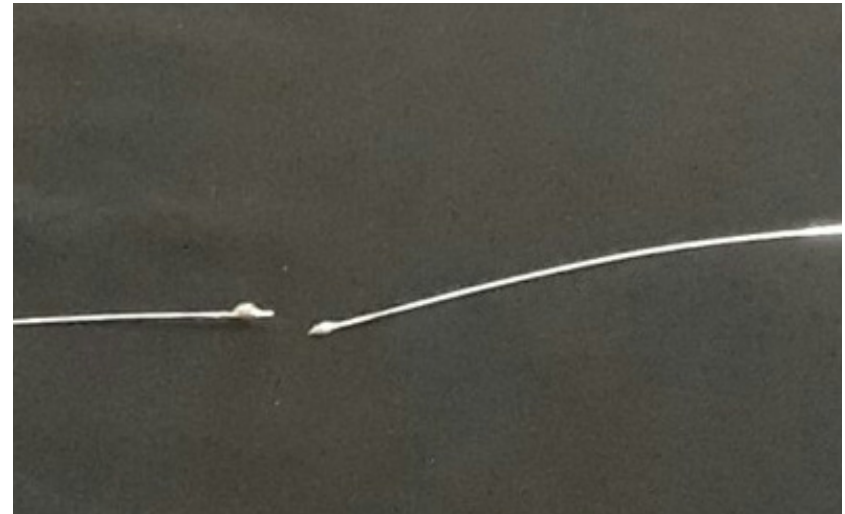

Fig.(4) The sample after the test

The test include : ultimate force and ultimate tensile strength ,both of these values were calculated by testing machine, special software which calculated the ultimate force first.

Elastic Modulus values were obtained by dividing a stress value.

E modulus $=$ stress $\backslash$ strain. ${ }^{(15)}$

Units of elastic modulus is Giga Pascal (Gpa)

\section{RESULTS}

\section{The ultimate tensile strength:}

All values of mean and standard deviation are listed in table (1). It can be seen that the mean tensile strength of control group is greater than that of soldered group ( figure 5). As well, there are highly significant differences between two groups $(p<0.01)$.

Table 1. mean and standard deviation of test groups for tensile strength

\begin{tabular}{|c|} 
Groups \\
\hline Tensile Strength /control group \\
Tensile Strength / test group
\end{tabular}

\begin{tabular}{|c|}
\hline Mean. \\
\hline 2033.60 \\
1307.40
\end{tabular}

Std. Deviation
27.056
226.746




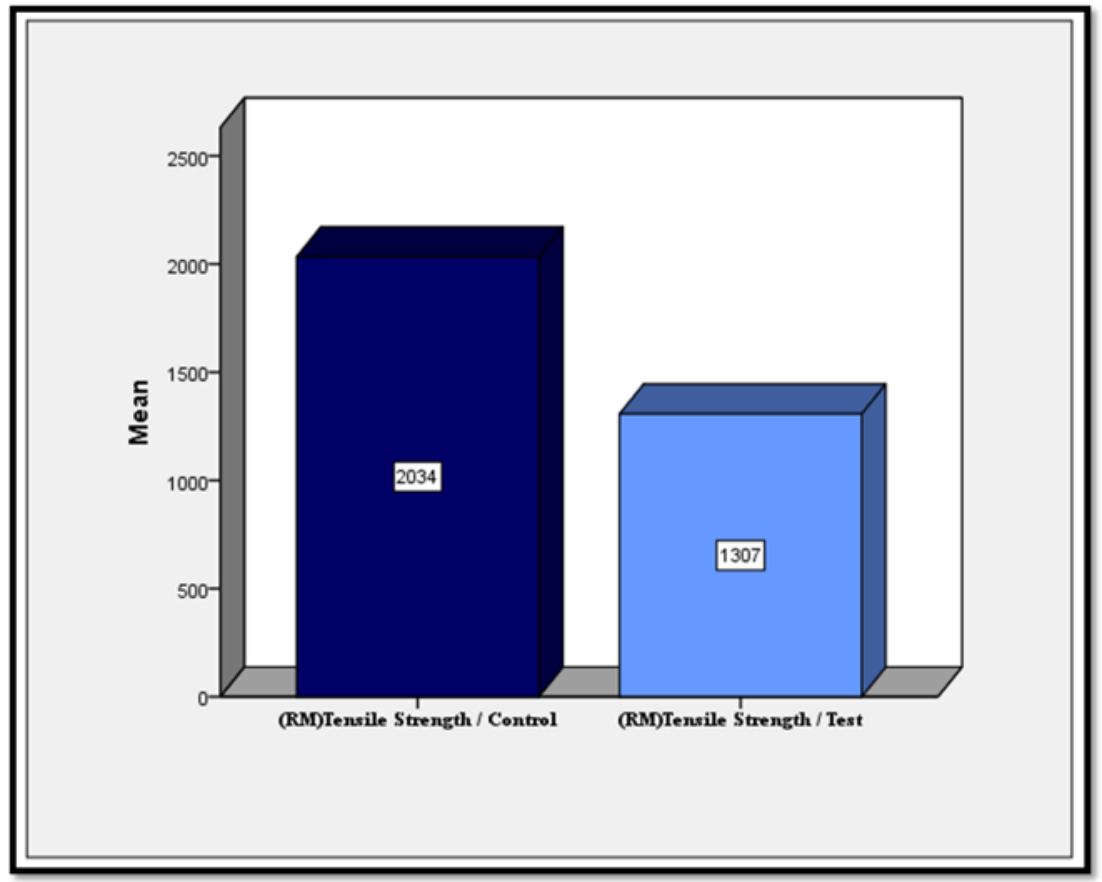

Figure (5): Mean of Tensile Strength of control\& test groups.

Table 2. independent $\mathrm{t}$ test

\begin{tabular}{|c|c|c|c|}
\hline & t-test & P-Value & \multicolumn{1}{|c|}{ C.S } \\
\hline (RM)Tensile Strength / Control - (RM)Tensile Strength / Test & 13.335 & .000 & $\mathrm{P}<0.01 \quad(\mathrm{HS})$ \\
\hline
\end{tabular}

:The elastic modulus measure of wires $r \quad$ ( figure 6). As well, there are highly significant All values of mean and standard deviation are differences between two groups $(p<0.01)$ as illustrated listed in table (2). The soldered group has the highest in table 4 ..

mean of elastic modulus than that of control group

Table 3. mean and standard deviation of test groups for Elastic modulus

\begin{tabular}{|c|c|c|}
\hline Groups & Mean. & Std. Deviation \\
\hline Elastic modulus /control group & 26.00 & 1.717 \\
\hline Elastic modulus /test group & 30.60 & 1.231 \\
\hline
\end{tabular}

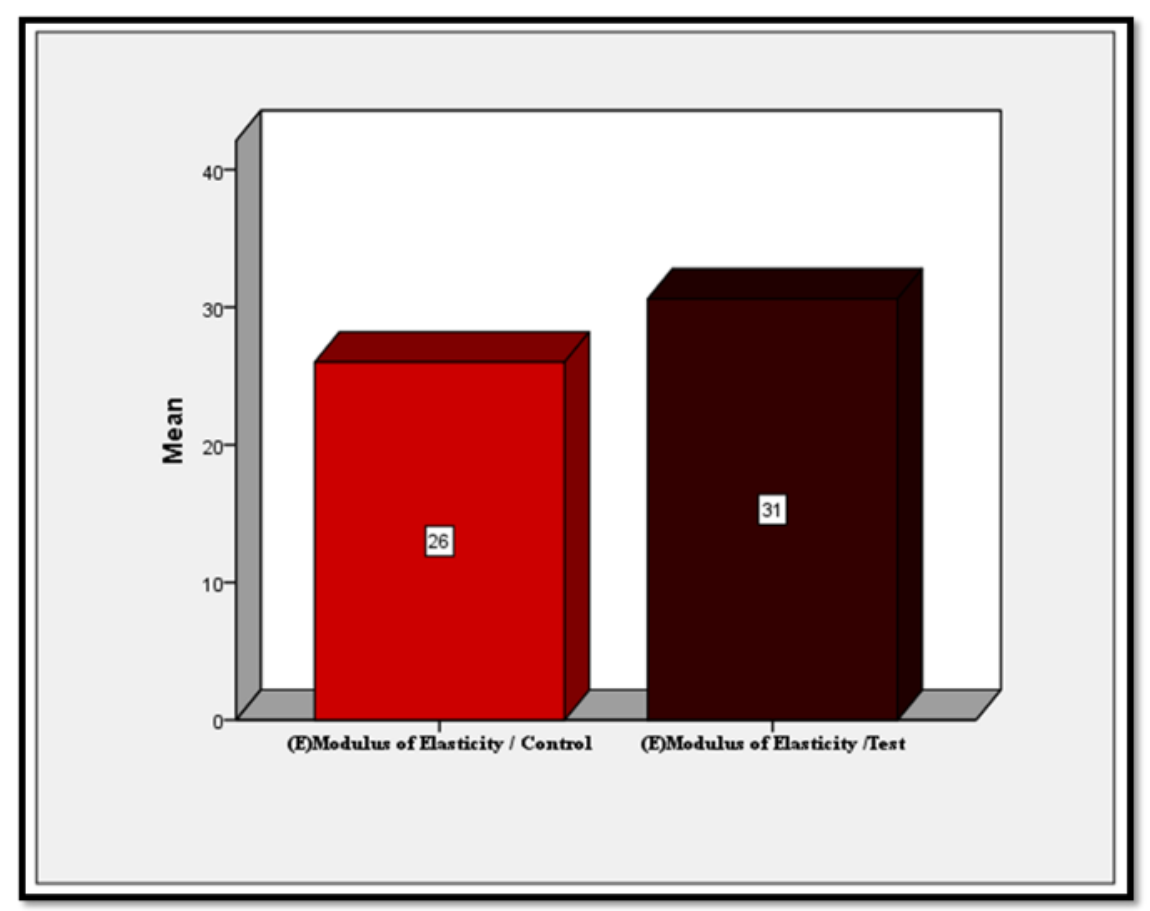

Fig. 6: Mean of elastic modulus of control\& test groups.: 
Table 4. independent t test

\begin{tabular}{|l|c|c|c|c|}
\hline (E)Modulus of Elasticity / Control - (E)Modulus of Elasticity /Test & 11.500 & .000 & $\mathrm{P}<0.01$ (HS) \\
\hline
\end{tabular}

\section{DISCUSSION}

Silver soldering of wires for the construction of appliances usually includes connection of wires with bands, other wires and crowns. It is vital that the solder wraps around the wires so that the solder has adequate mass to strengthen the joint. The edges of the solder ought to be feathered onto the wire so that no crack is left for agents to enter and start a corrosive action (16). The tensile strength of a silver soldered joint is affected by several factors including the metallurgy of the joint, the design of the joint, and the stress distribution within the joint. The strength of the joint should be as great as that of the parent metals ${ }^{(17)}$. The present study was conducted to assess and compare the mechanical properties (tensile strength and elastic modulus) of both the original and soldered wires. Stainless steel wires 0.036 inch (Remanium) were used in the current study. The results indicated that the ultimate tensile strength mean value for stainless steel wires was the greatest compared to soldered group. These results were similar to a study which carried out by Dua and Nandlal,(2004)(18) who found that Gloria (S.S.) wires had a lesser tensile strength of silver soldered joints. Independent sample t-test indicated that there is a highly-significant difference between the soldered wire and the original one. The ultimate tensile strength gave rise to greater values while the force divided on the less surface area and less value when force divided on higher surface area.In addition, the results showed that the elastic modulus was increased following soldering. The Independent sample t-test indicated that there is a highly-significant difference between the original and soldered wires.

\section{CONCLUSION}

The present study concluded the following points:

1.The soldered group produced a lower value of tensile strength.

2.The value of elastic modulus of soldered group is higher than that of control group. Overall, stainless steel wires have superior mechanical properties with regard to tensile strength and elastic modulus.

\section{REFERENCES}

1. 1Gawlik J.A., Mathieu G.P., and Hondurum S.: "The effects of tack welding and increasing surface area on the tensile strength of silver, electric and flame soldered stainless steet joints". J. Am. Acad. Ped. Dent., 1996; 18 (3).

2. O' Toole T.J., Furnish G.M. and Von Fraunhofer J.A.: "Tensile strength of soldered joints". J Prosthet Dent, 1985; 53 (3): $350-352$

3. Brown T., Mitchell R. and Barnie J. : "Evaluation of five silver soldering techniques". J Pedod 1982; 6: 235 - 43.

4. Cattaneo G., Wagnild G., Marshall G. and Watanabe L. "Comparison of tensile strength of solder joints by infrared and conventional torch technique". J Prosthet. Dent 1992; 68(1): 33-37.

5. Chaves M., Vermilyea S.G., Papazoglou E. and Brantely W.E. "Effects of three soldering techniques on the strength of high-palladium alloy solder joints". J Prosthet. Dent 1998; 79 (6): 677 - 84. 5

6. Cheng A.C., Chai J.Y., Gilbert J. and Jameson L.M. "Investigation of stiffness and microstructure of joints soldered with gas-oxygen torch and infrared methods". J. Prosthet. Dent 1994; 72 (1): 8 - 15.

7. Cheng A.C., Chai J.Y., Gilbert J. and Jameson L.M. "Mechanical properties of metal connectors soldered by gas torch versus an infrared technique". J Prosthodontic 1993;2(2): 103-109.

8. Gardiner J.H. and Aamdot A.C. : "Some aspects of soldering stainless steel: A metallurgical investigation". Dent Practit 1969; 20: 65 - 76 .

9. Gulkar I.A., Martini R.T., Zinner I.D. and Panno F.V. : "A comparison of hydrogen / oxygen and natural gas / oxygen torch soldering techniques". Int J Prosthodont 1994; 7: 258263.

10. Laird W.R.E. and Von Fraunhefer J.A.: "Silver soldered joints in stainless steel a comparative evaluation of techniques". Br Dent J 1972; 132: 263 - 267.

11. Limaverde Marcus A.R. and Stein R.S. : "Evaluation of soldered connectors of two base metal ceramic alloys". J Prosthet Dent 1994; 71: 339 - 344.

12. Tehini G.E. and Stein R.S. 1993. "Comparative analysis of two techniques for soldered connectors." J Prosthet Dent 1994; 69: 16- 19.

13. Wiskott H.W. A., Macheret R, Bussy R, Belser U.C. and Med Dent. : "Mechanical and elemental characterization of solder joints and welds using a gold-palladium alloy". J. Prosthet Dent 1997; 77: 607-616.

14. Phillips R.W. "Wrought base metal alloys wrought gold alloys. In skinners science of dental materials". 9th Ed.,Philadelphia: WB Saunders Co. 1991; 537 - 57. 14.

15. Ronald LS, John MP. Craig's Restorative Dental Materials,3rd ed. Philadelphia .Mosby;2012.

16. Adams J. W.: "Stainless Steel in Dentistry and Orthodontics". Dent Clin North Am 1958; 2: 783 - 88.

17. Rogers O.W. : "A metallographic evaluation of the stainless steel silver solder joint". Aus Dent J 1979; 24 (1): 13 - 16.

18. DUA R and NANDLAL B.A Comparative Evaluation of the Tensile Strength of Silver Soldered Jointsof Stainless Steel and Cobalt Chromium Orthodontic Wires with BandMaterial - An In vitro Study.Journal of Indian Society of Pedodontics and Preventive Dentistry 